\title{
Effects of Low-Power Microwave Fields on Seed Germination and Growth Rate
}

\author{
Lakshmappa Ragha ${ }^{1}$, Seema Mishra ${ }^{2}$, V. Ramachandran ${ }^{2}$, Manmohan Singh Bhatia ${ }^{3}$ \\ ${ }^{1}$ Electronics and Telecommunication Department, SIES Graduate School of Technology, Nerul, Navi-Mumbai, India; ${ }^{2}$ Bio Technol- \\ ogy Department, SIES Indian Institute of Environment Management, Nerul, Navi-Mumbai, India; ${ }^{3}$ Laser and Plasma Technology Di- \\ vison, Bhabha Atomic Research Centre, Mumbai, India. \\ Email: laxman.ragha@rediffmail.com, seema.mishra03@gmail.com, ramanv25@yahoo.com,monibhatia@rediffmail.com
}

Received January $2^{\text {nd }}, 2011$; revised March 14 ${ }^{\text {th }}$, 2011; accepted April 22 ${ }^{\text {nd }}, 2011$.

\begin{abstract}
Experiments were conducted to investigate the effects of low power microwave radiation on germination and growth rate in seeds. In the present paper, the bioeffects of low power (non-thermal intensity) microwave modulated with 1 $\mathrm{KHz}$ square wave have been studied. Experiments were performed in X-band frequencies using klystron based microwave test bench. Microwave parameters like frequency, power, exposure time and power density were varied while irradiating seed samples to study their influence on germination. The seed samples used for the experiment included wheat (Triticum aestivum), bengal gram (Cicer arietinum), green gram (Vigna radiate) and moth bean (Vigna Aconitifolia). Seed germination \%, plant height, root length and dry matter \% (biomass \%) were recorded and compared with control seeds. The effects of different treatments were found to be stimulating the germination and seedling vigour of plants especially in power and exposure time treatments while increase in frequency and power density has reduced the seed germination and seedling vigour. The effect also varied with the nature of seeds.
\end{abstract}

Keywords: Irradiated Seeds, Seed Germination \%, Low Power Microwave Effects, Exposure Time, Power, Power Density, X-Band Frequencies, Microwave Test Bench

\section{Introduction}

Widespread use of wireless telecommunication devices increased the exposure to radio and microwave frequency fields. These fields can cause damage depending on the power level, frequency, exposure duration, pulsed or continuous wave and the properties of exposed tissue (dielectric constants) etc. The unprecedented impact of mobile communications has given a strong motive for the present study in achieving a quantitative understanding of the relationships between the biological effects of microwaves and the physical variables. Internal effects from microwave exposure, especially low-level exposure, are not immediately noticeable. Recent research has suggested that microwaves may cause other, long-term health effects [1]. The general populace in India just recently began to use wireless communication technologies in so dense a way and the consequences of such a progress are not known. Hence, there is a need to understand the impact of wireless technology.

It is interesting to note that microwave power levels used for this study are comparable to the power levels being used in mobile phones. They are well below the permitted international safety standards for the general public. Since experiments on humans with microwaves are difficult, plants would be a better choice to study the overall effect on growth, productivity, biochemical and physiological parameters. Studies on plants do not need special facilities and have no statutory obligations. Hence, we have selected popular crops for our study. The germination of seeds and the growth rate are important features for maximizing the productivity that need a close observation.

There is some evidence that microwaves (300 MHz to $300 \mathrm{GHz}$ ) produces changes in the cell membrane's permeability and cell growth rate as well as interference with ions and organic molecules, like proteins [2]. Plants are essential components of a healthy ecosystem and have important role in the living world as main primary producers of food and oxygen; therefore it would be beneficial to investigate their interaction with today's increased exposure to radio and microwave frequency fields.

Microwaves are non ionizing radiations and are part of 
electromagnetic (EM) spectrum [3]. The characteristic of EM field is mainly described by its energy content, which is related to its frequency by $E=h f$, where $E=$ Electric field, $E=$ plank constant and $f=$ frequency. All EM wave consists of electrical $E$ and magnetic $H$ field components vibrating in phase and perpendicular to direction of propagation. EM waves differ depending upon frequency or wavelength. Frequency or corresponding wavelength defines the characteristics of EM wave. Frequency $(f)$ and wavelength $(\lambda)$ are connected by the following equation:

$$
\lambda=c / f
$$

where $c=3 \times 10^{8} \mathrm{~m} / \mathrm{s}$ is the speed of EM wave in vacuum. All the waves can be described mathematically by the following equation [4]:

$$
\mathrm{Y}(x, t)=\operatorname{Acos}\left(2 \pi t / T-2 \pi x / \lambda+\phi_{0}\right)
$$

where $A$ is the amplitude of the wave, $T$ its time period, $\lambda$ is its spatial wavelength and $\phi_{0}$ is a reference phase. The existence of electromagnetic wave, presumes time varying electric and magnetic fields connected in a way such that one creates other in a degree proportional to the rate of variation. The Maxwell's equation relates the electric and magnetic fields in different conditions.

A common way to describe the absorption of EM field in matter is to calculate the specific absorption rate (SAR). SAR is the measure of the absorption of non-ionizing EM radiation by living tissue. Mathematically it is defined as

$$
S A R=\sigma E^{2} / \rho \quad \mathrm{W} / \mathrm{Kg}
$$

Where $\sigma$ is the specific conductivity $(\mathrm{S} / \mathrm{m})$ of the body, $E$ is the Electric field intensity within the body $(\mathrm{v} / \mathrm{m})$ and $\rho$ is the density of the living tissue $\left(\mathrm{kg} / \mathrm{m}^{3}\right)$ [5].

The idea of controlling and influencing biological objects with the help of electromagnetic waves was stated by Devyatkov and Golant in early 60 s [6]. It was the beginning of intensive theoretical and experimental investigation in this direction. On the basis of scientific literature following regularities were formulated:

1) The effect of microwave frequency essentially depends on resonance character of the object.

2) Observed effects are not critical with regard to the incident energy density. This shows interaction between electromagnetic field and biological objects were nonlinear. At the same time there was not strong complete theory concerning these observing phenomena and the lack of the explanation of the resonance mechanisms.

Environmental conditions that effecting plant growth such as light, moisture, temperature etc are well documented and research papers based on these studies are extensively available. Plants are the appropriate environmental signals and plant studies raise less emotional concern than studies on humans or animals $[7,8]$. Studies related to the microwave bioeffects are a new and dynamic area of scientific research, involving both biotechnology and microwave engineering. Microwave bioeffects can be broadly classified into thermal and non thermal. It is well known that microwave fields have adverse biological effects at high power levels. But, bioeffects at low power levels have not been fully understood. Radiations are known to induce physiological and genetic modifications viz. production of various epidermal meristems in the hypocotyl, modifications of the proteome etc [9-12].

In view of this our study envisages the comparative effects of low power microwaves on seed germination and seedling vigour of different seeds of commercial crops. This study is an effort towards contribution to interdisciplinary research which has societal benefits also.

\section{Materials and Methods}

\subsection{Setup for Microwave Exposure}

Low power microwave signal was modulated with 1 $\mathrm{KHz}$ square wave. Seed samples were exposed to microwave radiations at $\mathrm{X}$-band frequencies. The total numbers of seeds were divided into two groups - control and irradiated. The study included ten seed samples each of wheat, bengal gram, green gram and moth bean both irradiated and control. Microwave components used in the experimental set up consist of: 1) X-band Klystron Power supply; 2) 2K25 Klystron tube with mount; 3) Isolator; 4) Frequency meter; 5) $20 \mathrm{db}$ Attenuator; 6) E-plane bend; 7) Microwave power meter; 8) Horn antenna; 9) Microwave absorber; 10) Seed samples and 11) Sample container. Other instruments used for the study included electronic balance, stop watch, string, scale, growing chamber for seed germination, permanent marker, zip-lock plastic baggies, water dropper and petri plates.

Microwave source parameters were varied one at a time by keeping remaining three parameters constant (Tables 1-4).Experimental set-up for low power microwave exposure was as shown in Plate 1. Power was controlled by attenuator and power density was varied by varying distance between horn antenna and seed samples. Plate 2 shows picture of germination and growth of irradiated and control (non irradiated) seeds.

\subsection{Exposure of Seeds to Low Power Microwave}

By introducing the seed (dielectric) in the electromagnetic field, a part of the energy of the field dissipates in the material. The energy dissipated in the material, under 
Table 1. Variation of Frequency.

\begin{tabular}{cccc}
\hline $\begin{array}{c}\text { Frequency } \\
(\mathrm{GHz})\end{array}$ & $\begin{array}{c}\text { Gap between } \\
\text { sample andAntenna } \\
(\mathrm{cm})\end{array}$ & $\begin{array}{c}\text { Power fed } \\
\text { to Antenna } \\
(\mathrm{dbm})\end{array}$ & $\begin{array}{c}\text { Exposure } \\
\text { Time } \\
\text { (Minutes) }\end{array}$ \\
\hline $\mathrm{f} 1=8.5$ & 1.0 & 5 & 30 \\
$\mathrm{f} 2=8.7$ & 1.0 & 5 & 30 \\
$\mathrm{f} 3=8.9$ & 1.0 & 5 & 30 \\
$\mathrm{f} 4=9.1$ & 1.0 & 5 & 30 \\
$\mathrm{f} 5=9.3$ & 1.0 & 5 & 30 \\
$\mathrm{f} 6=10.27$ & 1.0 & 5 & 30 \\
\hline
\end{tabular}

Table 2. Variation of Microwave Power.

\begin{tabular}{cccc}
\hline $\begin{array}{c}\text { Power fed to } \\
\text { Antenna (dbm) }\end{array}$ & $\begin{array}{c}\text { Gap between } \\
\text { sample and } \\
\text { Antenna (cm) }\end{array}$ & $\begin{array}{c}\text { Frequency } \\
(\mathrm{GHz})\end{array}$ & $\begin{array}{c}\text { Exposure } \\
\text { Time } \\
\text { (Minutes) }\end{array}$ \\
\hline-1.0 & 0.8 & 9.6 & 30 \\
0.5 & 0.8 & 9.6 & 30 \\
1.5 & 0.8 & 9.6 & 30 \\
2.5 & 0.8 & 9.6 & 30 \\
3.5 & 0.8 & 9.6 & 30 \\
\hline
\end{tabular}

Table 3. Variation of Exposure Time.

\begin{tabular}{cccc}
\hline $\begin{array}{c}\text { Exposure } \\
\text { Time, Minute } \\
(\mathrm{T})\end{array}$ & $\begin{array}{c}\text { Gap between } \\
\text { sample and } \\
\text { Antenna }(\mathrm{cm})\end{array}$ & $\begin{array}{c}\text { Power fed } \\
\text { to Antenna } \\
(\mathrm{dbm})\end{array}$ & $\begin{array}{c}\text { Frequency } \\
(\mathrm{GHz})\end{array}$ \\
\hline $\mathrm{T} 1=12$ & 0.8 & 5 & 9.6 \\
$\mathrm{~T} 2=16$ & 0.8 & 5 & 9.6 \\
$\mathrm{~T} 3=20$ & 0.8 & 5 & 9.6 \\
$\mathrm{~T} 4=24$ & 0.8 & 5 & 9.6 \\
$\mathrm{~T} 5=28$ & 0.8 & 5 & 9.6 \\
\hline
\end{tabular}

Table 4. Variation of Power density.

\begin{tabular}{cccc}
\hline $\begin{array}{c}\text { Gap between } \\
\text { sample and } \\
\text { Antenna (cm) }\end{array}$ & Frequency (GHz) & $\begin{array}{c}\text { Power fed to } \\
\text { Antenna (dbm) }\end{array}$ & $\begin{array}{c}\text { Exposure Time } \\
\text { (Minutes) }\end{array}$ \\
\hline $\mathrm{d} 1=1.5$ & 9.605 & 5 & 30 \\
$\mathrm{~d} 2=2.5$ & 9.605 & 5 & 30 \\
$\mathrm{~d} 3=3.5$ & 9.605 & 5 & 30 \\
$\mathrm{~d} 4=4.5$ & 9.605 & 5 & 30 \\
$\mathrm{~d} 5=5.5$ & 9.605 & 5 & 30 \\
\hline
\end{tabular}

the influence of the electromagnetic field, constitutes the dielectric losses. The measures $\varepsilon^{\prime}$ and $\varepsilon^{\prime \prime}$ depend on the frequency, moisture and temperature [13]. Following paragraphs explain research methodology chosen with an appropriate rationale.

This study focuses on the influence of X-band microwave fields on wheat, bengal gram, green gram and moth bean seed germination. These species were chosen because the period of germination is relatively low, the

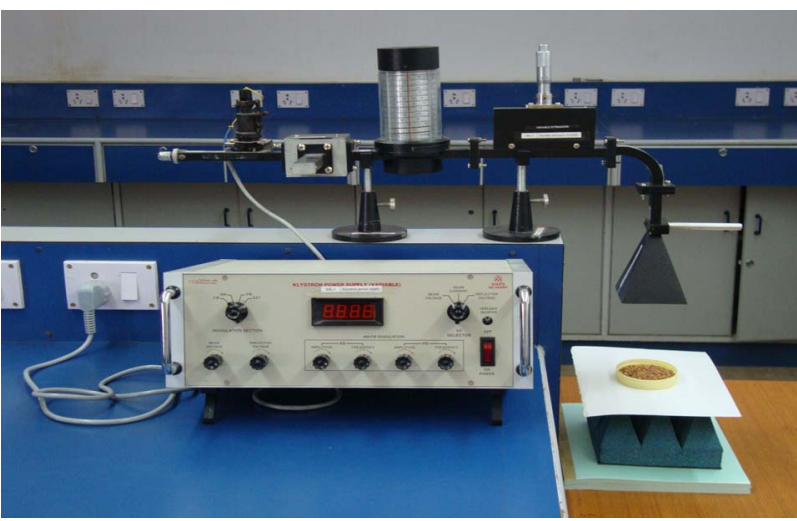

Plate 1. Experimental set up for microwave exposure using Klystron based microwave test bench.

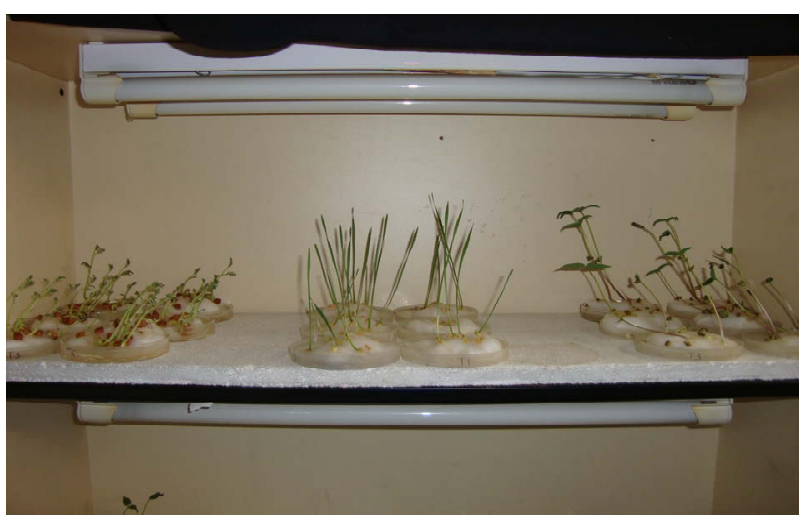

Plate 2. Germination and growth of irradiated and control (non irradiated) seeds.

experiment is held over a period of 7 days and also because of high protein content.

Seeds were processed in different regimes (frequency, power, power density and exposition time varied) (Tables 1-4). Non irradiated seeds were used as a control. Both microwave irradiated and control seeds (ten each) were put on cotton in separate sterilized petri plates for germination in a growth chamber as shown in Plate 2. Petri dishes, environmental conditions being kept under peer control, temperature and moisture levels, being $23^{\circ} \mathrm{C}$ and $98 \%$ humidity respectively. After germination the young plantlets development was conducted in the same controlled laboratory conditions $\left(t=22 \pm 0.5^{\circ} \mathrm{C}\right.$, illumination-10 h: $14 \mathrm{~h}$ light/dark cycle and 90\% humidity) and all plant samples were supplied only with deionized water during the experiment-about $15 \mathrm{ml}$ daily per petri dish. Plant length of the 7 days old plantlets was measured. The average lengths of three replicates were calculated for each batch of seeds. After taking fresh weight of three plants, plants were kept for drying at $60^{\circ} \mathrm{C}$ upto constant weight. Dry matter percentage was calculated as per the Equation (4) [14]. 
Dry matter $(\mathrm{DM}) \%=$ (weight of dry sample/weight of fresh sample) $\times 100$

\section{Results and Discussion}

The results discussed in this section are the effects of various parameters like exposure time, power, power density and frequency on seed germination and growth rate. Analysis is based on the results shown in Figures 1-4, Table 5 and Table 6.

In case of wheat sample with increase in microwave frequency germination is seem to improve upto $60 \%$ whereas no germination observed at lower frequencies including control. High frequency stimulates seed germination for wheat. Similar but more pronounced effect noticed in the case of bengal gram. Seed germination is seem to improve even at lower frequencies as compared to control. With increase in frequency seed germination increases as compared to control. The extent of improvement is marginal and not as pronounced as in the case of wheat and bengal gram. Similar trend is noticed in the case of moth bean.

In case of wheat sample higher power intensely affects germination. With increase in microwave power germination is hampered and steadily decreases. Similar trend is noticed in case of green gram and moth bean. In case of bengal gram with increase in microwave power germination on the other hand improves. But at the highest power used no germination observed.

Decrease in seed germination is observed in all seed samples with increase in exposure time from 12 minute to 28 minute as compared to control group (Table 3). Decrease in seed germination is observed in almost all seed samples with decrease in power density from d1-d5 (Table 4) as compared to control group. But variation in power density has less influence on germination in case of green gram sample.

\subsection{Effect of Microwave Frequency on Plant Height, Root Length and Biomass \% (DM \%)}

In the case of wheat, with increase in frequency from 8.5 $\mathrm{GHz}$ to $9.3 \mathrm{GHz}$ (Table 1) no seedling growth is observed as in the case of control also. When the frequency of microwave increased further to $10.27 \mathrm{GHz}$ seedling growth was observed indicating stimulating effect.

In the case of bengal gram, the stimulating effect of microwave radiation is observed in a more pronounced manner as compared to wheat. There was no seedling in the control whereas seedling observed even at frequencies as low as $8.5 \mathrm{GHz}$. With increase in frequency the plant height and root length is observed to decrease where as biomass \% (DM \%) is increased significantly. It could be due to accumulation of the nutrients in the plants in view of induced stress. It is also corroborated by [15].

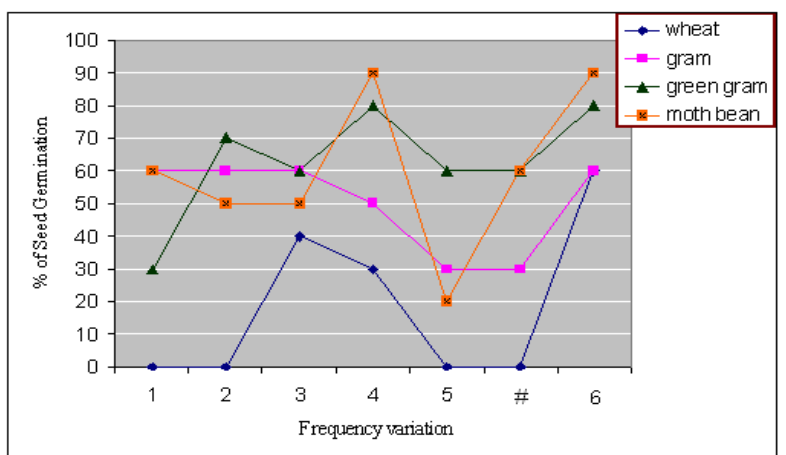

Figure 1. Seed germination Vs Frequency.

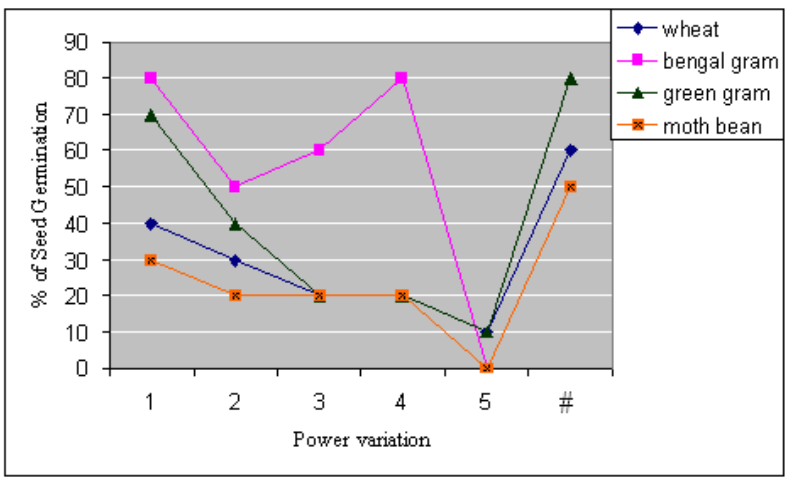

Figure 2. Seed germination Vs Power.

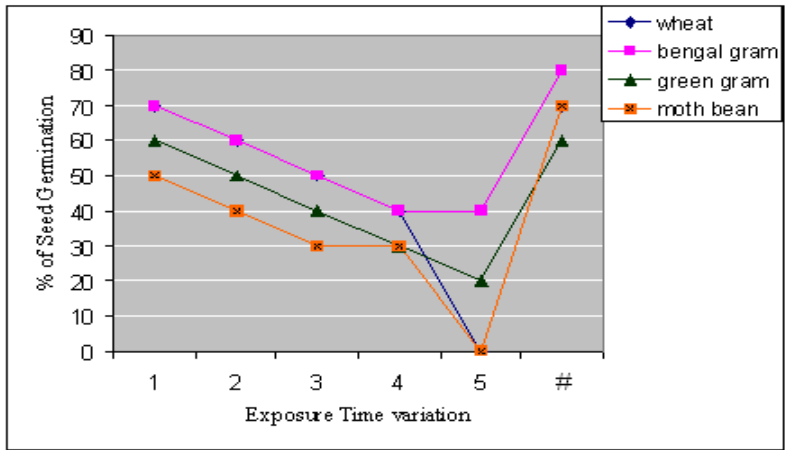

Figure 3. Seed germination Vs Exposure time.

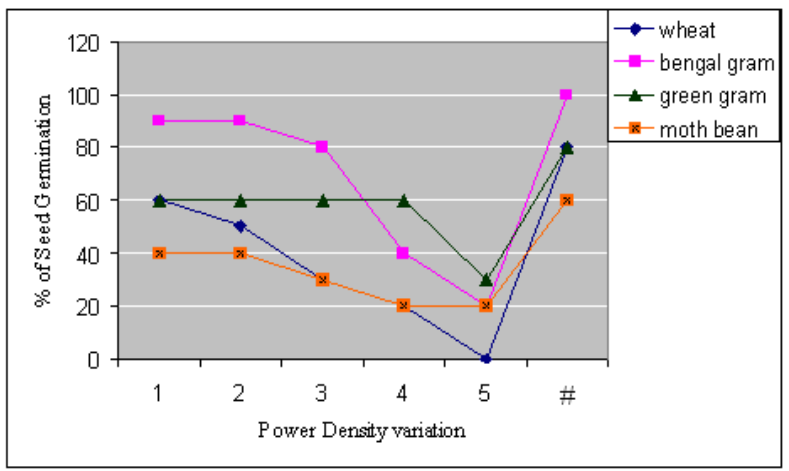

Figure 4. Seed germination Vs Power density. 
Table 5. Variation of Plant growth with frequency and Power treatment.

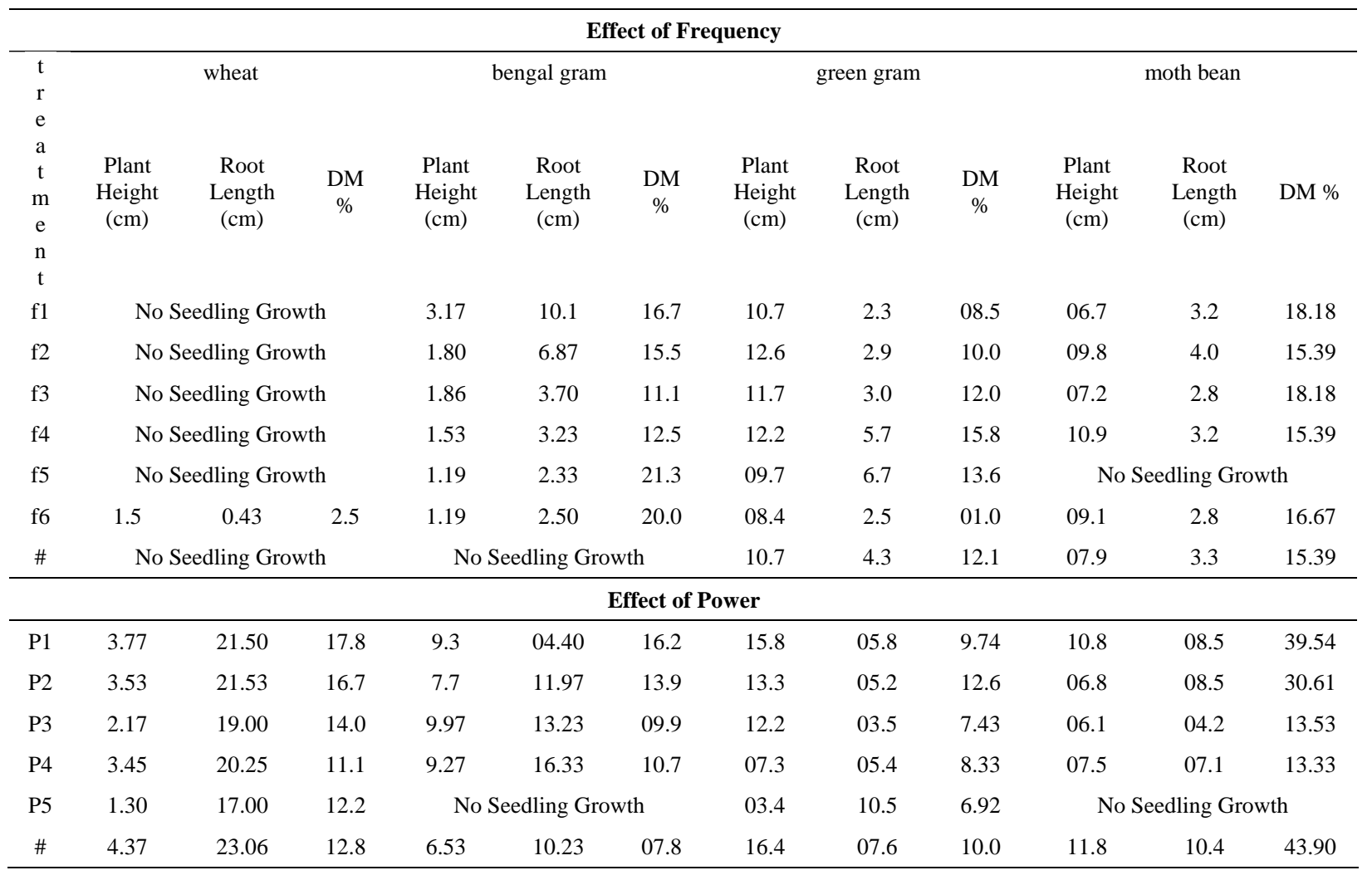

Table 6. Variation of Plant growth with Power Density and Exposure Time treatment.

\begin{tabular}{|c|c|c|c|c|c|c|c|c|c|c|c|c|}
\hline $\begin{array}{l}\mathrm{t} \\
\mathrm{r} \\
\mathrm{e}\end{array}$ & \multicolumn{3}{|c|}{ wheat } & \multicolumn{3}{|c|}{ bengal gram } & \multicolumn{3}{|c|}{ green gram } & \multicolumn{3}{|c|}{ moth bean } \\
\hline $\begin{array}{c}\mathrm{a} \\
\mathrm{t} \\
\mathrm{m} \\
\mathrm{e} \\
\mathrm{n} \\
\mathrm{t}\end{array}$ & $\begin{array}{l}\text { Plant } \\
\text { Height } \\
(\mathrm{cm})\end{array}$ & $\begin{array}{l}\text { Root } \\
\text { Length } \\
(\mathrm{cm})\end{array}$ & $\begin{array}{c}\mathrm{DM} \\
\%\end{array}$ & $\begin{array}{l}\text { Plant } \\
\text { Height } \\
(\mathrm{cm})\end{array}$ & $\begin{array}{c}\text { Root } \\
\text { Length } \\
\text { (cm) }\end{array}$ & $\begin{array}{c}\mathrm{DM} \\
\%\end{array}$ & $\begin{array}{l}\text { Plant } \\
\text { Height } \\
(\mathrm{cm})\end{array}$ & $\begin{array}{c}\text { Root } \\
\text { Length } \\
(\mathrm{cm})\end{array}$ & $\begin{array}{c}\mathrm{DM} \\
\%\end{array}$ & $\begin{array}{l}\text { Plant } \\
\text { Height } \\
(\mathrm{cm})\end{array}$ & $\begin{array}{l}\text { Root } \\
\text { Length } \\
(\mathrm{cm})\end{array}$ & $\mathrm{DM} \%$ \\
\hline \multicolumn{13}{|c|}{ Effect of Power Density } \\
\hline $\mathrm{d} 1$ & 4.0 & 9.2 & 24.6 & 10.33 & 10.67 & 30.7 & 18.06 & 7.17 & 20.0 & 09.8 & 9.00 & 61.54 \\
\hline $\mathrm{d} 2$ & 3.8 & 6.0 & 23.9 & 9.93 & 12.67 & 20.6 & 19.77 & 6.23 & 08.6 & 10.3 & 4.60 & 11.76 \\
\hline d3 & 3.2 & 3.8 & 24.5 & 9.86 & 09.10 & 17.7 & 19.23 & 6.70 & 10.0 & 06.0 & 3.73 & 63.64 \\
\hline $\mathrm{d} 4$ & 1.2 & 3.2 & 44.4 & 6.07 & 05.70 & 19.5 & 14.47 & 3.93 & 08.0 & 07.9 & 6.35 & 64.29 \\
\hline d5 & \multicolumn{3}{|c|}{ No Seedling Growth } & 4.05 & 03.75 & 17.7 & 16.66 & 3.17 & 06.7 & 07.9 & 5.85 & 66.67 \\
\hline \# & 4.1 & 6.3 & 50.0 & 11.83 & 11.63 & 29.1 & 19.33 & 6.07 & 21.9 & 11.6 & 8.33 & 43.08 \\
\hline \multicolumn{13}{|c|}{ Effect of Exposure Time } \\
\hline $\mathrm{T} 1$ & 4.1 & 8.4 & 72.5 & 6.5 & 08.7 & 20.4 & 11.4 & 6.4 & 26.9 & 6.17 & 13 & 66.66 \\
\hline $\mathrm{T} 2$ & 2.8 & 8.9 & 106 & 5.5 & 06.8 & 23.3 & 11.6 & 5.9 & 32.0 & 5.97 & 5.7 & 53.33 \\
\hline T3 & 2.2 & 8.9 & 134 & 6.9 & 05.6 & 11.6 & 10.3 & 3.4 & 12.0 & 3.35 & 3.2 & 37.04 \\
\hline $\mathrm{T} 4$ & 2.6 & 9.0 & 44.8 & 5.3 & 06.2 & 52.9 & 05.3 & 1.7 & 9.52 & 4.25 & 2.5 & 52.50 \\
\hline T5 & \multicolumn{3}{|c|}{ No Seedling Growth } & 5.2 & 08.7 & 05.5 & 01.8 & 1.1 & 20.0 & \multicolumn{3}{|c|}{ No Seedling Growth } \\
\hline \# & 3.4 & 8.5 & 6.9 & 7.6 & 10.1 & 20.9 & 12.9 & 4.7 & 24.8 & 7.40 & 6.1 & 69.23 \\
\hline
\end{tabular}


More plant height would have better photosynthetic rate that may have maximum biomass also. Better root length could help in absorbing more nutrients and water from deeper inside the soil. This approach would be beneficial in water scarce areas.

In the case of green gram, the seedling is marginally improved with increase in frequency. The plant height, root length and biomass \%, all have improved. This indicates that green gram is more responsive to increase in microwave frequency. Similar observations are seen in case of moth bean.

\subsection{Effect of Microwave Power on Plant Height, Root Length and Biomass \% (DM \%)}

In the case of wheat, with increase in power from $-1 \mathrm{dbm}$ to $3.5 \mathrm{dbm}$ decrease in seedling growth is observed as compared to control (Table 2). The plant height, root length and biomass \%, all have decreased. This indicates that wheat is most affected due to increase in microwave power.

In the case of bengal gram, with increase in power from $-1 \mathrm{dbm}$ to $2.5 \mathrm{dbm}$ there is increase in seedling growth as compared to control. Whereas higher biomass $\%$ is observed as compared to control but biomass \% decreased with increase in power. No seedling growth is observed at $3.5 \mathrm{dbm}$ indicating pronounced effect for higher power.

In case of green gram, root length and biomass \% decreased with increase in microwave power as compared to control indicating effect on seedling growth. But higher root length is observed compared to control at highest power level used (3.5 dbm). This effect will be useful for plants in water scarce areas as longer roots will be helpful in extracting more water and nutrients from soil.

In case of moth bean plant height, root length and biomass $\%$ has decreased with increase in microwave power as compared to control.

\subsection{Effect of Microwave Exposure Time on Plant Height, Root Length and Biomass (DM \%)}

In this study exposure time is varied from 12 minutes to 28 minutes in steps of 4 minutes while other microwave parameters like power, frequency, power density are kept constant (Table 3).

In case of wheat, plant height decreased and no significant change in root length observed with increase in exposure time from 12 minutes to 24 minutes as compare to control. But huge increase in biomass \% is observed with increase in exposure time from 12 minutes to 20 minutes as compared to control. However, decrease in seedling growth observed at 24 minutes exposure time and no seedling growth at highest exposure time used that is 28 minutes indicating threshold value.

In case of bengal gram, plant height, root length decreased with increase in exposure time as compare to control. Biomass \% observed is $53 \%$ at 24 minute exposure time as compare to $21 \%$ of control indicating that bengal gram is more sensitive to this exposure time. There is no significant change in biomass \% for other exposure times as compared to control.

In case of green gram, decrease in trend is observed for plant height, root length and biomass \% with increase in exposure time as compared to control.

In case of moth bean, plant height, root length and biomass \% is decreased with increase in exposure time as compared to control. No seedling growth is observed at highest exposure time used that is 28 minutes.

\subsection{Effect of Microwave Power Density on Plant Height, Root Length and Biomass (DM \%)}

In this study gap between the sample and antenna (radiating source) is varied from $1.5 \mathrm{~cm}$ to $5.5 \mathrm{~cm}$ in steps of $1 \mathrm{~cm}$ while other microwave parameters like power, frequency and exposure time are kept constant (Table 4). This variation indicates variation in power density. Power density decreased as we increase the gap between the sample and antenna.

In case of wheat, less seedling growth is observed as compared to control at all the power densities used in the study. There is reduction in plant height, root length and biomass \% as compared to control with corresponding reduction in power density from $\mathrm{d} 1 \mathrm{-} \mathrm{d} 4$ indicating better seedling growth at higher power densities. No seedling growth was observed at lowest power density, d5.

In case of bengal gram, there is reduction in plant height, root length and biomass \% as compared to control with corresponding reduction in power density from $\mathrm{d} 1$ d5 indicating better seedling growth at higher power densities. Higher root length is observed at higher power densities as compared to control.

In case of green gram, root length and biomass \% is decreased with decrease in power density indicating better seedling growth at higher power densities. There is no significant variation in plant height with decrease in power density as compared to control.

In case of moth bean, seedling growth is less as compared to control for all the power densities used. There is upto $23 \%$ increase in biomass \% as compared to control for all the power densities used except d2 indicating that moth beans are more responsive to higher power densities.

\section{Conclusions}

Seeds were processed in different regimes to study their influence on germination and growth rate. The effects of 
different treatments were found to be stimulating the germination and seedling vigour of plants especially in power and exposure time treatments. Decrease in trend is observed for seed germination, seedling vigour, plant height, root length and biomass \% for most of the samples used with increase in microwave power and exposure time as compared to control. Similar observation is made but with decrease in power density indicating better seedling growth at higher power densities. High frequency stimulates seed germination for most of the samples as compared to control. Only biomass \% observed is significant with increase in frequency for most of the samples used as compared to control. The effect also varied with the nature of seeds. Since this study indicates microwave influence on seed germination and growth rate it must be affecting the humans who are using mobile phones. This study can be the basis for possible microwave effects on humans and animals. More studies in this direction needs to be conducted for scientific claim. However, our study is novel in its approach but further studies are needed to evaluate the effect of low power microwave on physiological and biochemical parameter.

\section{Acknowledgements}

The authors would like to thank higher authorities of SIES, Mumbai for providing necessary facilities to carry out this research study.

\section{REFERENCES}

[1] J. C. Lin, "Evaluating Scientific Literature on Biological Effects of Microwave Radiation,” IEEE Microwave Magazine, Vol. 5, No. 1, March 2004, pp. 34-37. doi:10.1109/MMW.2004.1284940

[2] Eugen Ungureanu, Calin Lucian Maniu, Smaranda Vântu, Igor Cretescu, "Consideration on the Peroxidase Activity during Hippophae Rhamnoides Seeds Germination Exposed to Radiofrequency Electromagnetic Field Influence," Analele stiintifice ale Universitattii, Alexandru Ioan Cuza, Sectiunea Genetica si Biologie Moleculara, TOM X, 2009, pp. 29-34

[3] “Non Ionizing Radiations,” Internet Available: http://www.who.int/peh

[4] F. T. Ulaby, "Fundamentals of Applied Electromagnetics,” 2004 Medaia Edition, p. 14.

[5] L. K. Ragha and M. S. Bhatia, "A Feasibility Study of Fractional Spherical Head Model for SAR Evaluation,” IETECH Journal of Communication Techniques, Vol. 3,
No: 3, 2009, pp. 051-057.

[6] V. A. Karpovich, V. N. Rodionova and G. Ya. Lepyan, "Application of Microwave Energy in Modern Biotechnologies,” MSMw'2001 Symposium Proceedings, Kharkov, 4-9 June 2001, pp. 909-910.

[7] M. C. Verdus, M. Thellier and C. Ripoll, "Storage of Environmental Signals in Flax: Their Morphogenetic Effect as Enabled by a Transient Depletion of Calcium," The Plant Journal, Vol. 12, No. 6, December 1997, pp. 1399-1410. doi:10.1046/j.1365-313x.1997.12061399.x

[8] A. Vian, C. Henry-Vian and E. Davies, "Rapid and Systemic Accumulation of Chloroplast mRNA Binding Protein Transcripts after Flame Stimulus in Tomato,” Plant Physiology, Vol. 121, No. 2, 1999, pp. 517-524. doi:10.1104/pp.121.2.517

[9] M. Tafforeau, M. C. Verdus, R. Charlionet, A. CabinFlaman and C. Ripoll, "Two-Dimensional Electrophoresis Investigation of Short Term Response of Flax Seedlings to Cold Shock," Electrophoresis, Vol. 23, No. 15, August 2002, pp. 2534-2540. doi:10.1002/1522-2683(200208)23:15<2534::AID-ELPS 2534>3.0.CO;2-M

[10] M. Tafforeau, M. C. Verdus, V. Norris, G. White, M. Demarty, M. Thellier and C. Ripoll, "SIMS Study of the Calcium-Deprivation Step Related to Epidermal Meristem Production Induced in Flax by Cold Shock or Radiation from a GSM Telephone," Journal of Trace and Microprobe Techniques, Vol. 20, No. 4, 2002, pp. 611-623. doi:10.1081/TMA-120015622

[11] M. Tafforeau, M. C. Verdus, V. Norris, G. J. White, M. Cole, M. Demarty, M. Thellier and C. Ripoll, "Plant Sensitivity to Low Intensity $105 \mathrm{GHz}$ Electromagnetic Radiation,” Bioelectromagnetics, Vol. 25, No. 6, September 2004, pp. 403-407. doi:10.1002/bem.10205

[12] M. Tafforeau, M. C. Verdus, V. Norris, C. Ripoll and M. Thellier, "Memory Processes in the Response of Plants to Environmental Signals,” Plant Sign Behav., Vol. 1, 2006, pp. 9-14. doi:10.4161/psb.1.1.2164

[13] V. D. Soproni, F. I. Hathazi, M. N. Arion, C. O. Molnar, and L. Bandici, “Aspects Regarding the Adapting and Optimization of Mixed Drying Systems Microwave-Hot Air for the Processing of Agricultural Seeds," PIERS Proceedings, Beijing, 23-27 March 2009, pp. 210-213.

[14] S. K. Thimmaiah, "Standard Methods of Biochemical Analysis,” Kalyani Publishers, New Delhi, 1999, p. 534.

[15] A.Wahid, S. Gelani, M. Ashraf and M. R. Foolad, "Heat Tolerance in Plants: An Overview," Environmental and Experimental Botany, Vol. 61, No. 3, December 2007, pp. 199-223. doi:10.1016/j.envexpbot.2007.05.011 